\title{
Finite Element Analysis of an Ammunition Bracket
}

\author{
Gaoqiang $\mathrm{Ma}^{1}$, Jiacheng Zhou $^{2}$ \\ ${ }^{1}$ The 713 Research Institute of CSIC, Zhengzhou, 450015, China \\ ${ }^{2}$ The 713 Research Institute of CSIC, Zhengzhou, 450015, China
}

\begin{abstract}
In this paper, a certain type of ammunition bracket was studied, the stress distribution under working load is calculated by static analysis and display dynamic analysis, the stress distribution result show that the maximum load during the working cycle is the instantaneous impact force. Through ANSYS software, Goodman theory method was used to modify the stress, the fatigue life of the bracket and the safety factor of each position of the bracket are calculated. It can provide for life prediction and reliability research of the projectile support.
\end{abstract}

\section{Introduction}

With the continuous improvement of naval combat power, the country has higher and higher requirements for naval guns, so the overall reliability of naval guns must be improved. To accomplish this task, we must first improve the reliability of each part of the naval gun. The ammunition bracket plays a vital role in the realization of the function of the ammunition lifter. Its function is to lift the ammunition from the drum to the receiving mechanism of the transfer position. In order to meet the requirement of high burst rate of fire, a certain type of naval gun adopts a closed chain reciprocating bombing method. If the bullet carrier fails, it will not only affect the function of the naval gun, but also cause safety problems, which may cause the ammunition fell and exploded. Therefore, analyzing the stress distribution of the ammunition bracket, optimizing and improving the ammunition bracket and correctly grasping the life of the ammunition bracket has great theoretical and practical significance to improve its safety. This paper uses ANSYS to perform finite element analysis on the elastic support, obtains the stress distribution of the elastic support under working load, and calculates the fatigue life of the elastic support.

\section{Static analysis}

\subsection{Establishment off finite element model}

During analysis, if the structure is too complex, it will affect the division of the grid and reduce the quality of the grid, resulting in slow calculation and time-consuming calculations. Moreover, local details have little effect on the analysis of structural forces. Therefore, some reasonable simplifications were made when modeling.
The finite element model is established as shown in Figure1.

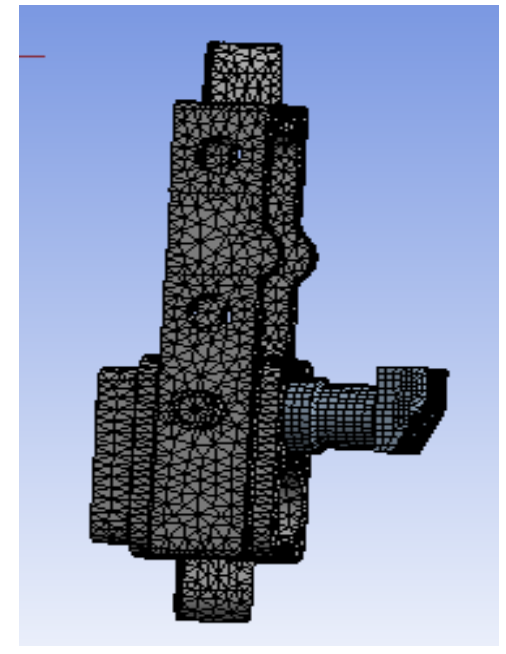

Figure 1. Finite element model of ammunition bracket component

\subsection{Load application and caluction}

Since the weight of the ammunition bracket itself is very small compared to the ammunition, it can be ignored. The load received by the ammunition bracket during the working process is the weight of the ammunition and the resistance during the movement. The load on the ammunition bracket is applied to the action surface of the shrapnel in a uniform force, as shown in Figure 2.

zhongchuan@hn.csic.com.cn 


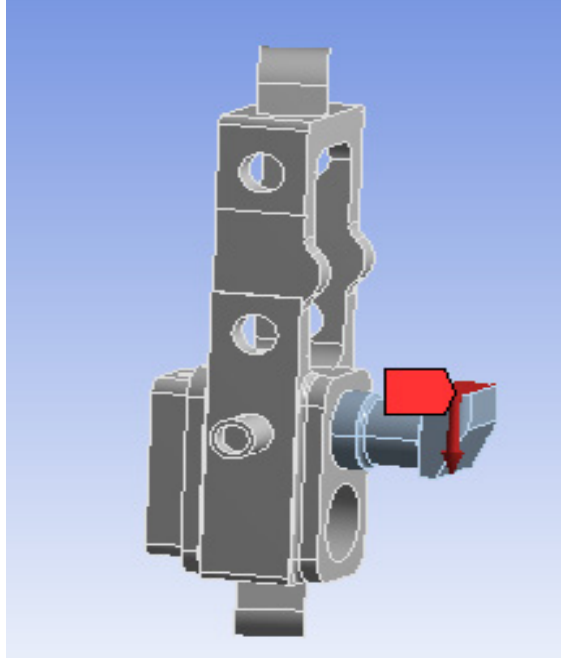

Figure 2. Schematic diagram of the load applied on the ammunition bracket surface

The static analysis stress cloud diagram and displacement cloud diagram of the ammunition bracket are calculated, as shown in Figure 3 and Figure 4.

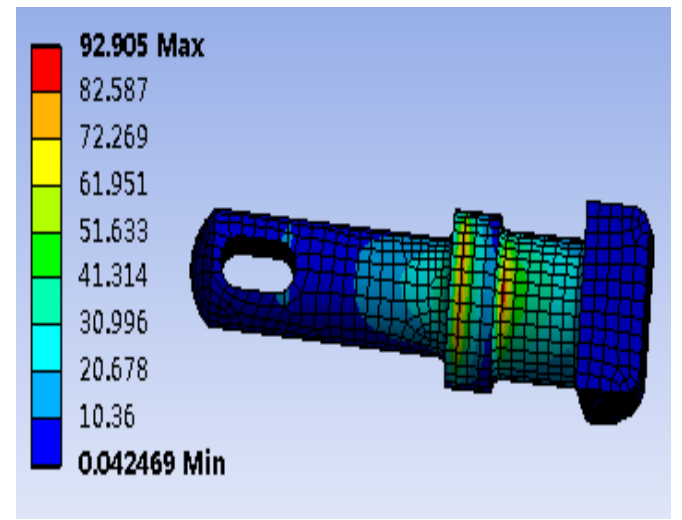

Figure 3. Stress cloud diagram

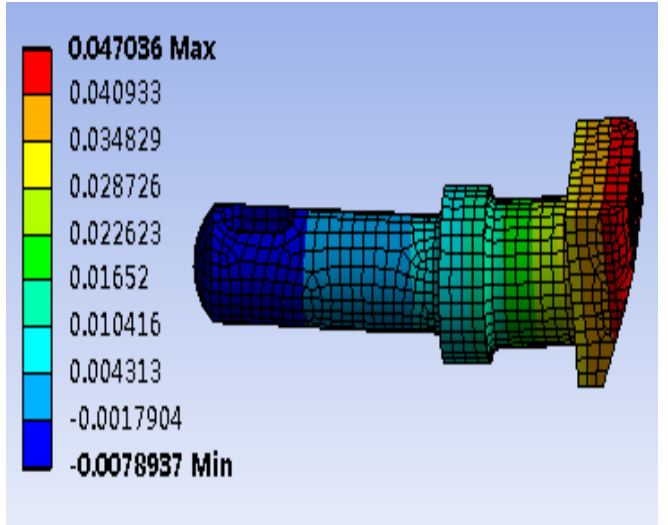

Figure 4. Displacement cloud diagram

From the calculation results, it can be seen that the maximum stress generated by the static force of the ammunition bracket during the working process is 92.9MPa, the maximum displacement is $0.047 \mathrm{~mm}$.

\section{Display dynamic anslysis}

\subsection{Establishment of finite element model}

It is not easy to measure the instantaneous load of the ammunition bracket when it comes into contact with the ammunition. Calculation simulation is a common method at present. In this paper, dynamic analysis is used to calculate the instantaneous load of the ammunition bracket when it hits the ammunition at a certain speed.

First, a simplified model of the pulley trolley, ammunition bracket and ammunition was established in the creo software, imported into ANSYS, and a finite element model was established, as shown in Figure 5.

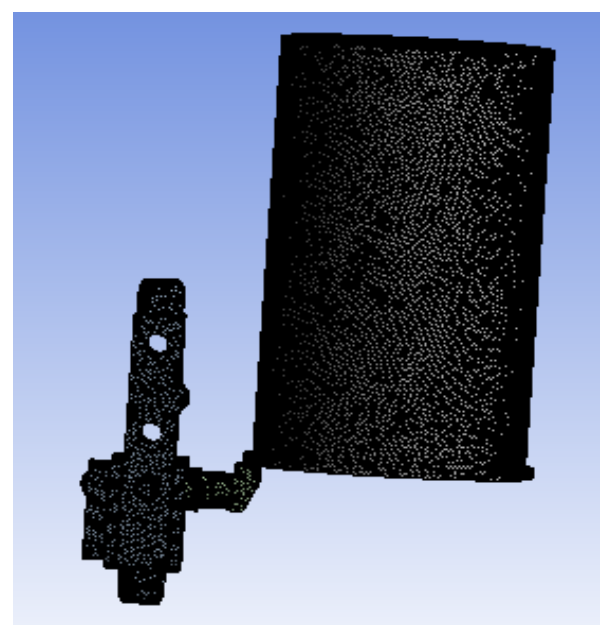

Figure 5. Schematic diagram of dynamic analysis finite element

\subsection{Display dynamic analysis calculation}

Through the Explicit Dynamics module of ANSYS software, assume the initial speed of the ammunition bracket and the pulley body, and consider the motion state of the three under normal operation. When setting the boundary conditions, set the ammunition bracket, the pulley trolley and the ammunition in a completely free state. The stress cloud diagram of the elastic support obtained through analysis is shown in Figure 6.

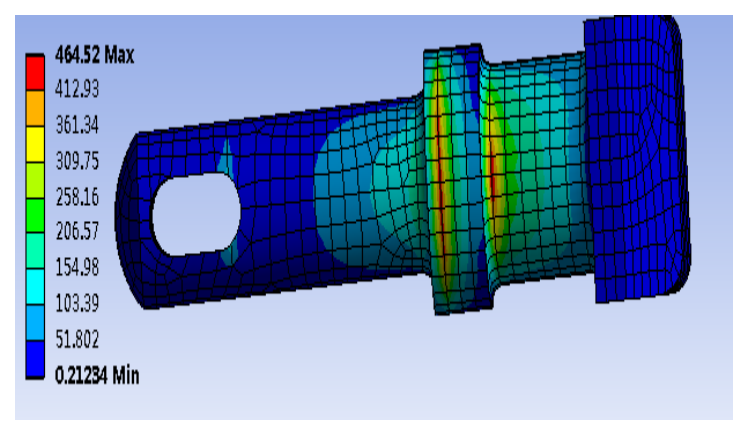

Figure 6. Stress cloud diagram

In the actual impact process, the impact of the head of the ammunition bracket under the force of the doleis downward, and at the same time, the tail of the 
ammunition bracket continues to move upward relative to the head and act on the pulley trolley. The movement guide section in the middle of the ammunition bracket Subject to the upward force of the pulley trolley, according to the theoretical analysis, the stress in the contact part between the ammunition bracket and the pulley trolley is the largest.

From the calculation results, it can be seen that the maximum stress value of the ammunition bracket under the instantaneous load is $464.5 \mathrm{MPa}$, and the maximum stress position is shown in Figure 6, and the position is consistent with the theoretical analysis.

The stress statistics of static analysis and display dynamic analysis are shown in Table 1 . The yield strength requirement of the ammunition bracket material is $640 \mathrm{MPa}$, which meets the strength requirement.

Table 1. Stress table

\begin{tabular}{cccc}
\hline & $\begin{array}{c}\text { Minimum stress } \\
(\mathrm{MPa})\end{array}$ & $\begin{array}{c}\text { Maximum stress } \\
(\mathrm{MPa})\end{array}$ & $\begin{array}{c}\text { Mean stress } \\
(\mathrm{MPa})\end{array}$ \\
\hline $\begin{array}{c}\text { Display dynamic } \\
\text { analysis }\end{array}$ & 0.2123 & 464.52 & 51.434 \\
\hline Static analysis & 0.0425 & 92.9 & 10.86 \\
\hline
\end{tabular}

\section{Fatigue analysis}

The purpose of fatigue analysis is to obtain the remaining life of the ammunition bracket. From the beginning to the failure of the ammunition bracket, there are roughly three processes: stable operation, continuous performance degradation, and finally failure. Accurate remaining life prediction provides a guarantee for the development of appropriate preventive maintenance and replacement strategies. After the initial damage of the ammunition bracket, its degradation phenomenon is obviously intensified with time, and finally fails when the degradation amount reaches a certain value.

From the results of static analysis and display dynamic analysis, it can be known that the instantaneous force experienced by the ammunition bracket during impact is the maximum load during its working life. The instantaneous force calculated by the display dynamic analysis is applied to the working surface of the ammunition bracket for fatigue analysis.

In fatigue analysis, for parts subjected to symmetrical loads, the average stress of the parts is 0 , that is, the stress ratio is -1 . Since the cyclic load received by the ammunition bracket during the working process is nota symmetrical load, the average stress is not equal to zero. The average stress is subjected to stress correction. In this paper, Godman method is used for stress correction. Goodman's stress correction equation is:

$$
\frac{S_{a}}{S_{e}}+\frac{S_{m}}{S_{u}}=1
$$

Where $\mathrm{Sa}=$ fatigue strength when the average stress is Sm under a specific number of cycles

$\mathrm{Sm}=$ average stress

$\mathrm{Se}=$ Fatigue strength when the average stress is 0 under a specific number of cycles

$\mathrm{Su}=$ tensile strength

The life formula for calculating the fatigue strength of parts is

$$
K_{N}=m \sqrt{\frac{N_{0}}{N}}
$$

$$
K_{N}=\frac{K_{\alpha e} \sigma_{\epsilon}[s]}{\sigma_{-1}-\psi_{\sigma} \sigma_{m}[s]}
$$

Where $\sigma_{\epsilon}$ and $\sigma_{\mathrm{m}}$ are respectively the stress amplitude and average stress acting on the calculated section of the part; [s] is the allowable safety factor for fatigue strength calculation.

$\mathrm{K}_{\mathrm{N}} \leq 1$, calculated according to formula (3-3) means infinite life design, at this time the number of cycles is greater than or equal to $\mathrm{N}_{0}$; calculated $\mathrm{K}_{\mathrm{N}}>1$ means finite life calculation, and the number of cycles is calculated according to formula (3-2) N.

The whole life analysis method is also called the SN method. It is based on the stress of the structure. It uses the rain flow cycle counting method and the Miner theory to analyze the life of the analyzed mechanism, and selects different analysis parameters such as the confidence parameter and the average stress correction method., Predict the life of the structure.

Enter the S-N curve of the ammunition bracket material, and calculate the fatigue life of the ammunition bracket to be 9216 times, as shown in Figure 7.

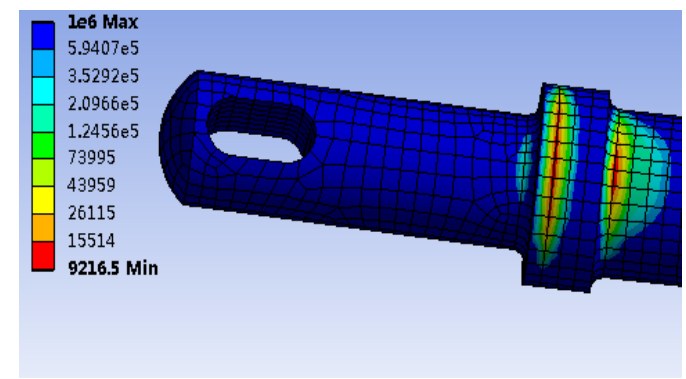

Figure 7. The fatigue life cloud diagram of ammunition bracket

The safety factor of the ammunition bracket structure at various positions within its fatigue life calculated from the fatigue calculation shows that the safety factor is the lowest in the guide section of the ammunition bracket and the transition section of the cylindrical transition section of different sizes, as shown in Figure 8. 


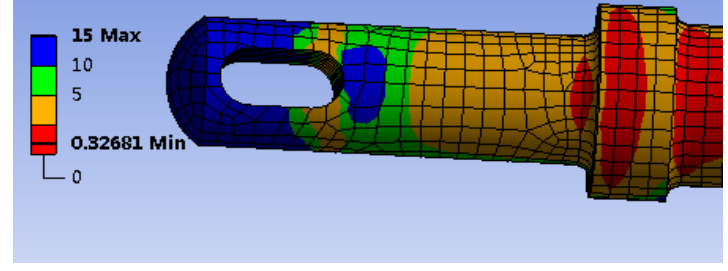

Figure 8. The safety factor diagram of each position of the ammunition bracket

From the calculation results of the ammunition bracket, it can be seen that although the fatigue life of the ammunition bracket is 9,216 times, the deformation of the ammunition bracket will affect the normal operation of the ammunition bracket. Therefore, the research on the life of the ammunition bracket deformation process needs further research. When studying the deformation life, the area with the lowest safety factor should be focused on. At the same time, it is also necessary to optimize and improve the area of the lower safety factor of the ammunition to improve the life and reliability of the ammunition bracket.

Improving the fatigue strength of the structure can effectively increase the fatigue life of the structure. The methods to improve the fatigue strength include: surface cold working strengthening, surface heat treatment strengthening, and structural improvement.

\section{Conclusion}

In this paper, static analysis and display dynamic analysis are carried out on the ammunition bracket, and the fatigue life of the shrapnel is analyzed with the maximum load, and the following conclusions are drawn.

(1) Working under normal load, the strength of the ammunition bracket meets the requirements.

(2) The maximum load received by the ammunition bracket during its life span is the instantaneous load at the time of impact.

(3) Fatigue calculations have obtained the fatigue life of the ammunition bracket and the safety factor of each position.

(4) Provide references for life prediction and reliability research of the ammunition bracket, which can guide the next step in the research on the deformation life of the ammunition bracket.

\section{References}

1. Wang Jian, Sun Zhili, Yu Zhenliang, Chai Xiaodong. Remaining life interval estimation of mechanical parts based on support vector machine, [J], Journal of Northeastern University, 2016.7

2. Qingqi Wang, Fatigue Life Calculation of Mechanical Parts,[J],Journal of Central South University of Mining and Metallurgy,1989.1

3. Tao Zhang, Overview of the research and development of fatigue life analysis methods, [A], Agricultural Equipment and Vehicle Engineering, 2018.11

4. Zhang Ke, Song Xuding, Wanyipin, Overview of
Methods for Improving the Fatigue Strength of Mechanical Parts, [A], Southern Agricultural Machinery, 2019.2 